\title{
КРИМИнологИя
}

\section{ОБ ОПЫТЕ КРИМИНОЛОГИЧЕСКОГО ИССЛЕДОВАНИЯ МИГРАЦИОННОЙ БЕЗОПАСНОСТИ АЗИАТСКОЙ ЧАСТИ РОссиИ}

\author{
Никитенко И.В.
}

Аннотация: Опьт исследования криминологических аспектов обеспечения миграционной безопасности Азиатской части России, позволяет утверждать, что миграџионная ситуация в разных регионах Российской Федерации неоднородна, как и различны, порождаемые подобной неоднородностью криминогенные факторы. Это же в свою очередь даёт основания предположить о различиях в характере и интенсивности миграционных процессов, что в свою очередь может влиять на динамику воспроизводства соответствующих криминогенных факторов.Однако цзентральное место в теме исследования отводилось именно «миграционной безопасности». Методологический подход к изучению проблем криминологического обеспечения миграционной безопасности азиатского макро региона в пределах Российской Федерации, основывался на объединении в единую смысловую конструкиию научно-отраслевой и географической компоненты исследуемых вопросов. Обосновывается комплекс мер, направленных на зашиту общественных и государственных интересов от соответствующих вызовов, что в общих чертах, можно охарактеризовать, криминологической парадигмой обеспечения миграционной безопасности России с учетом региональных особенностей некоторых территорий. Достижение цуелей такого исследования связанно с реализаиией конкретных методологических подходов, а также решением комплекса научных задач. Подобным опытом мы хотим, поделится с читателем.

Ключевые слова: Азиатская часть России, безопасность, защчищенность, иммиграция, криминологическое обеспечение, криминогенный фон, криминологическая типология, миграционные процессы, угрозы, факторы.

Широкий комплекс криминогенных факторов, обусловленных перманентным ростом иностранной миграции, либерализацией иммиграционного режима и соответственно постепенным снижением управляемости иммиграционных процессов способствуют формированию соответствующих угроз российскому обществу и государству. Это явление в научной литературе и публицистике, называют - «миграционная опасность», а его альтернативу - «миграционная безопасность». Однако ни то, ни другое не получило в современной криминологии должного теоретического обоснования. Не сложился и соответствующий нормативно-правовой статус обозначенных феноменов.

Перечисленные обстоятельства и побудили к теоретической разработке проблемы криминологического обеспечения миграционной безопасности Азиатской части России, как территории с наиболее выраженными демографическими и иными взаимосвязанными проблемами, с учётом того, что результаты исследования при соответствующей модификации могут быть экстраполированы и на другие регионы России. 
Методологический подход к изучению проблем криминологического обеспечения миграционной безопасности азиатского макро региона в пределах Российской Федерации, основывался на объединении в единую смысловую конструкцию научно-отраслевой и географической компоненты исследуемых вопросов. Однако центральное место в теме исследования отводилось именно «миграционной безопасности».

Подобная постановка проблемы, позволила сформулировать и главную исследовательскую гипотезу, которая состояла в предположении о том, что эффективность миграционной политики зависит, в том числе, и от наличия эффективной системы криминологического обеспечения миграционной безопасности государства, то есть способности защитить национальные интересы от криминальных угроз, возникающих вследствие миграционных процессов. В свою очередь, надежность и эффективность криминологического обеспечения миграционной безопасности Азиатской части России, территории с ярко выраженными региональными особенностями, возможны при следующих условиях:

- феномен миграционной безопасности осознаётся как предмет криминологического исследования, что позволит преобразовать его в форму криминологической дефиниции наряду с иными системообразующими компонентами национальной безопасности;

- миграционная безопасность включена в систему национальной безопасности на нормативноправовом уровне;

- система криминологического обеспечения миграционной безопасности региона формируется с учетом его геополитических, этнокультурных, демографических, экономических и иных особенностей;

- эффективном международном сотрудничестве в области противодействия незаконной миграции и оказания взаимной правовой помощи, включая реадмиссии и экстрадиции правонарушителей.

Главный из поставленных нами вопросов заключался в осознании криминологической сути феномена миграционной безопасности и целесообразности наделения его нормативно-правовым статусом по аналогии с другими компонентами системы национальной безопасности, которые уже нашли отражение в ряде соответствующих нормативных актов и политических деклараций[1].

Второй из вопросов, состоял в осмыслении важности развития криминологической теории миграционной безопасности, обеспечивающей эффективное противодействие воспроизводству криминогенным факторам, источником которых являются миграционные процессы.

И третий из поставленных вопросов следует отнести к обоснованию целесообразности проведения такого исследования в формате отдельно взятой территории Российской Федерации, позволяющей сосредоточить внимание на геополитических, демографических, социальных, экономических, а также иных региональных особенностях Азиатской части России.

Краткий ответ на первый из поставленных вопросов, состоит в том, что впервые криминологически значимые аспекты демографической и миграционной безопасности были обозначены в 80-е годы XX века одной из экспертных комиссий Госплана СССР в связи с событиями в Нагорном Карабахе.

Так, в целях выяснения причин известного межнационального конфликта был проведен анализ изменений национального состава населения региона, который показал, что стремительное увеличение удельного веса азербайджанского населения, расцененное как демографическая экспансия, явилось результатом не только особенностей его естественного воспроизводства, но в первую очередь следствием неуправляемых миграционных процессов[2]. Однако в дальнейшем институт миграционной безопасности так и не получил должного нормативно-правового оформления. Само же словосочетание «миграционная безопасность» стало активно применяться в научной и политической лексике.

Основываясь на доводах о наличии выраженных институциональных признаков, характеризующих феномен миграционной безопасности, естественно и логично заключить, что это находящееся в процессе формирования правовое явление, к которому применима социальная градация уровней безопасности, соответствующая общепринятой формуле - «безопасность личности, общества и государства». Такая возможность подкрепляется уже имеющимися теоретическими выводами о юридической целесообразности нормативного закрепления миграционной безопасности в качестве структурного компонента национальной безопасности, что подтверждается наличием широкого спектра угроз, многие из которых имеют криминологическое значение и уже сегодня отнесены к компетенции уголовного законодательства, либо рассматриваются как потенциально общественно-опасные и имеют реальные перспективы криминализации. 
Миграционная безопасность в наиболее общем значении может быть определена как основанная на нормах международного и национального права защищенность личности, общества и государства от угроз (опасностей), возникающих вследствие и по поводу миграции населения.

Установление юридических признаков миграционной безопасности, как одного из системных компонентов национальной безопасности, дает основания рассматривать это явление в качестве предмета криминологического исследования. А его криминологическая парадигма складывается на основании соответствующих положений теории криминологической безопасности, сообразно которой, миграционная безопасность может быть представлена как - состояние объективной защищенности интересов личности, общества и государства от криминальных опасностей, порождаемых различного рода криминогенными факторами, возникающими вследствие миграционных процессов, а также осознание людьми своей защищенности от подобных угроз. Такая позиция, по сути, является ответом на второй из трёх основных вопросов, определивших криминологический формат нашего исследования[3].

В обоснование целесообразности проведения исследования в формате Азиатской части России, следует отметить, что для такого крупного и полиморфного государства, с беспрецедентной по протяженности государственной границей, и вместе с тем, контрастной неоднородностью геополитических, демографических, экономических, социальных и иных условий, сегодня ещё не представляется возможным разработать универсальную модель криминологического обеспечения миграционной безопасности без учёта региональных особенностей, его многочисленных административно-территориальных образований. В связи с этим, было принято решение исследовать проблемы криминологического обеспечения миграционной безопасности в масштабах азиатского макрорегиона России, площадь которого около 13,1 млн. км ${ }^{2}$, что примерно равно $76 \%$ её территории, на которой расположены три федеральных округа состоящих из двадцати шести субъектов федерации, на которых проживает до 27 \% страны. Однако же плотность населения в Азиатской части России значительно ниже чем в Европейской и одна из наименьших в мире, до 1,7 жителей на 1 км² $^{2}$, средняя же по России составляет до 8,3 жителей на 1 км².

Следует отметить и то, что географический срез нашего исследования не исключает возможности выявления и универсальных свойств, а также общих закономерностей изучаемого феномена, что позволяет экстраполировать некоторые из итоговых выводов, и на другие регионы Российской Федерации.

Теперь, когда определена концепция исследования, позвольте представить краткий обзор его основных этапов, методологических подходов, теоретических обобщений и итоговых выводов.

На первом этапе исследования был установлен комплекс институциональных признаков миграционной безопасности, позволяющих рассматривать данную категорию как юридический феномен и предмет криминологического исследования. Однако, в связи с тем, что она, как компонент системы национальной безопасности, распространима на три социальных уровня, что свидетельствует о ее чрезвычайно широком значении и не способствует сосредоточенности исследования на достижении поставленных целей. Было принято решение рассматривать миграционную безопасность в узком (ограниченном) и широком (распространительном) вариантах[4]. Это же, в свою очередь позволило «зафиксировать» границы исследования, сводимые к решению конкретных задач криминологического обеспечения миграционной безопасности российского общества и государства. Представляется, что подобный подход особенно важен для криминологического исследования, так как специфика анти-криминогенного воздействия предполагает чёткое осознание того, о каком именно из уровней безопасности идёт речь.

Решение вышеназванной методологической задачи позволило конкретизировать предмет исследования, что в свою очередь оказало существенное влияние на его результаты.

Ретроспективный анализ развития миграционных процессов в Азиатской части России, с точки зрения их влияния на состояние миграционной безопасности государства вообще и криминологической составляющеё этого явления в особенности, позволил прийти к выводу о наличии исторической преемственности, взаимообусловленности, а во многом и аналогичности явлений связанных с миграционными процессами сегодня. Исторический опыт свидетельствует о тесной, корреляционной зависимости между характером осуществляемой государством миграционной политики, самой миграцией и миграционной безопасностью. История освоения азиатских территорий России связана как с позитивным, так и негативным влиянием иностранной миграции. Однако миграция из ряда стран Юго-восточной Азии, и особенно из Китая, в разные исторические периоды оказывала небла- 
гоприятное воздействие криминогенный фон в азиатском макро-регионе. Возникающие же проблемы часто решались репрессивными методами, связанными с использованием полицейских и даже военных средств.

Очевидно, что многие из вопросов, связанных с криминологическим обеспечением миграционной безопасности Азиатской части России, не утратили актуальность и сегодня. Так демографические, геополитические, экономические и иные особенности освоения региона способствовали активизации миграционных процессов. Однако приоритеты интенсивного заселения отдаленных территорий деактуализировали проблему развития государственного миграционного контроля, что, в свою очередь, создавало условия для роста нелегальной миграции и связанной с этим явлением преступности.

На основании экспертных оценок, контентанализа разных информационных источников, а также наблюдений за изменениями миграционной ситуации в различных регионах РФ можно с определенной долей уверенности сказать о наличии существенных противоречий между реально складывающейся ситуацией с точки зрения присутствия криминогенных факторов, оказывающих влияние на рост преступности мигрантов (включая и миграционную преступность, то есть связанную с процессом незаконной миграции) и теми ее показателями, к которым сегодня апеллирует официальная статистика. Так, ежегодный прирост объема иностранной миграции на 250-300 тыс. чел. (миграционное сальдо), который естественно сопровождается ростом и ее нелегальной составляющей, на фоне постепенного снижения миграционной убыли (миграционное нетто), в обычных условиях является объективным фактором, способствующим росту миграционной преступности, пропорционально доли прироста миграционного сальдо. Кроме этого, сегодня нет достаточных оснований утверждать о появлении новых факторов, способствующих снижению названного сегмента преступности.

Практика обеспечения миграционной безопасности государства, а также развитие соответствующих положений миграционного, административного и уголовного законодательств, свидетельствуют, что уже сегодня в России, сформирована система противодействия нелегальной миграции, работа над совершенствованием которой продолжается. Однако среди наиболее распространенных проблем нормативно-правового, а, следовательно, и правоприменительного характера в сфере обеспечения криминологической составляющей миграционной безопасности, можно назвать следующие: наличие системных и редакционных недостатков соответствующих институтов уголовного права; не всегда адекватный подход при определении степени и характера общественной опасности преступлений посягающих на миграционную безопасность государства; недостатки в организации и функционировании самой системы обеспечения миграционной безопасности. Кроме этого, следует обратить внимание и на не всегда адекватную миграционную политику в целом, которая должна соответствовать складывающимся геополитическим, демографическим, экономическим и социальным реалиям. Она не должна быть тенденциозно рестрикционной или либеральной, но при этом учитывающей интересы общественной и государственной безопасности.

В результате комплексного исследования указанных проблем был сформулирован ряд теоретических положений и практических рекомендаций представляющих криминологическую парадигму концепции миграционной безопасности государства.

1. Криминологический компонент миграционной опасности представляет собой криминогенные проявления миграционных процессов, заключающихся в возможном или начавшимся причинением существенного вреда правоохраняемым интересам личности, общества и государства путем нарушения норм миграционного законодательства.

2. Миграционная безопасность Российской Федерации есть часть системы национальной безопасности и обладает необходимыми для юридической категории признаками:

- обусловлена наличием источника опасности и исходящих от него реальных и потенциальных угроз, значительная часть из которых имеет криминогенный характер;

- выражается во взаимодействии субъектов и объектов безопасности;

- обладает свойствами, позволяющими применять к данному явлению соответствующие методы правового регулирования.

3. Миграционная безопасность представляет собой многоуровневую систему, соответствующую принятой теорией безопасности формуле - «безопасность личности, общества и государства». Подобный уровневый подход позволяет определить методы и средства антикриминального воздействия, которые должны максимально точно соответствовать объектам миграционной безопасности. На основании выработанной 
концепции, под криминологическим обеспечением миграционной безопасности понимается основанное на достижениях современной криминологии решение теоретических и прикладных задач по созданию и поддержанию социально приемлемого уровня защищённости интересов личности, общества и государства от детерминируемых миграционными процессами криминальных опасностей.

4. Криминологические аспекты миграционной безопасности определяются характером угроз, общая совокупность которых условно дифференцируется на имеющие непосредственное криминологическое значение и иные. Криминологической парадигмой миграционной безопасности государства являются соответствующие положения теории криминологической безопасности, на основании которой миграционная безопасность представляет собой состояние объективной защищенности интересов личности, общества и государства от криминальных угроз, возникающих вследствие миграционных процессов, а также осознание людьми своей защищенности от подобных опасностей.

5. Система криминологического обеспечения миграционной безопасности государства представляет собой организованную, в соответствии с нормами международного и национального права, совокупность специальных органов, средств и методов защиты государственных и общественных интересов от криминальных угроз, источниками которых являются миграционные процессы.

Целью функционирования данной системы является нейтрализация подобных угроз, а её содержание образуют следующие компоненты:

- нормативно-правовое обеспечение, включающее мероприятия по формированию и реализации нормативно-правовых актов, направленных на защиту общественных и государственных интересов от преступных посягательств, связанных с внешней миграцией;

- информационное и идеологическое обеспечение, предполагающее позитивное развитие миграционной политики государства, общественного правосознания и ценностных ориентиров, направленных на декриминализацию миграционных процессов;

- научное и методическое обеспечение, направленное на теоретическое обоснование, разработку и внедрение в практику новых форм, средств и методов противодействия криминальным опасностям, возникающим вследствие миграционных процессов;

- организационное обеспечение, создающее условия для эффективной деятельности субъектов, наделённых функциями по защите правоохраняемых интересов от криминальных угроз, создаваемых миграционными процессами;

- технологическое обеспечение, позволяющее использовать передовые достижения науки и техники в предупреждении криминальных опасностей, источниками которых являются миграционные процессы;

- материально-ресурсное обеспечение, предполагающее обоснование, изыскание и покрытие материальных расходов в связи с функционированием системы криминологического обеспечения миграционной безопасности.

6. Общности и различия преступлений, причиняющих вред интересам миграционной безопасности государства и представляющих криминальную угрозу этому компоненту национальной безопасности, позволяют дифференцировать подобные деяния на две основные группы:

- преступления, непосредственно посягающие на установленный государством порядок миграции населения;

- преступления, обеспечивающие или сопровождающие процесс незаконной миграции, создающие условия или являющиеся способом реализации незаконной миграции, но с точки зрения систематизации норм уголовного закона, причиняющие вред иным правоохраняемым объектам.

7. Подобная категоризация преступлений позволяет дифференцировать их субъекты и способствует дальнейшему развитию криминологической теории личности преступника, посягающего на миграционную безопасность государства. Coобразно представленной градации преступлений, виновные в совершении подобных деяний, условно классифицируются на две основные группы:

- субъекты преступлений миграционного характера, а именно лиц, правовой статус которых определен нормами миграционного законодательства РФ (иностранные мигранты, представители приглашающей или принимающей сторон);

- лица, не отнесенные миграционным законодательством к субъектам миграционных правоотношений, но при определенных условиях являющиеся субъектами уголовно-наказуемых деяний, обеспечивающих или сопровождающих нарушения миграционного законодательства РФ (субъекты ряда должностных преступлений и преступлений против порядка управления, деяния которых способствуют незаконной миграции).

8. Наиболее опасным проявлением незаконной миграции, как основной угрозы миграционной безопасности государства, является миграци- 
онная преступность, которая в разных регионах Азиатской части России качественно неоднородна и различна по ряду показателей, отражающих её динамику. Это в первую очередь обусловлено региональной спецификой миграционных процессов, неравномерностью распределения иммиграционных потоков, а также изменениями миграционной политики Российской Федерации. В большинстве регионов Азиатской части России имеют место существенные различия между основными трендами преступности и ее миграционной компонентой, что позволяет прийти к выводу о наличии собственных криминогенных факторов, влияющих на динамику миграционной преступности.

9. Криминологическое исследование проблем обеспечения миграционной безопасности в масштабах пространственно-территориальной единицы предполагает выявление наиболее типичных, имеющих криминологическое значение признаков, позволяющих группировать либо дифференцировать территории относительно социально-криминологических типов. В регионах Азиатской части России существует устойчивая взаимосвязь между миграционной привлекательностью, интенсивностью иммиграционных процессов и воспроизводством криминогенных факторов, влияющих на состояние миграционной безопасности. В соответствие с указанными критериями, регионы Азиатской части России можно сгруппировать по трём основным типам:

- регионы с высокой интенсивностью иммиграционных процессов, негативно влияющих на воспроизводство криминогенных факторов;

- регионы со средней интенсивностью иммиграционных процессов, негативно влияющих на воспроизводство криминогенных факторов;

- регионы с низкой интенсивностью иммиграционных процессов, негативно влияющих на воспроизводство криминогенных факторов.

10. Исторический опыт свидетельствует о высокой корреляционной зависимости между характером миграционной политики, динамикой миграционных процессов и состоянием миграционной безопасности государства. Особенности освоения и исторического развития Азиатской части России, а также сложившиеся геополитические, демографические и экономические условия в этом макро-регионе оказали существенное влияние на характер миграционных процессов и связанных с ними криминогенных проявлений, что обусловливает целесообразность учёта региональных особенностей при формировании и развитии системы криминологического обеспечения миграционной безопасности государства. В свою очередь, динамика, структура, а также иные качественные и количественные характеристики внешних миграций населения в Азиатской части России существенно влияют на структуру населения, включая этнический и культурный баланс, уровень социальной напряжённости и криминогенный фон в этом макро-регионе. Данный факторный комплекс необходимо учитывать в развитии региональной миграционной политике, что в свою очередь является важным условием для эффективного функционирования системы криминологического обеспечения миграционной безопасности государства в целом.

11. Эффективное функционирование системы криминологического обеспечения миграционной безопасности России возможно при условии учёта региональных особенностей входящих в её состав территорий. Потенциал развития этой системы заключается в решении следующих организационных, юридических, информационных и технологических задач:

- путем заимствования зарубежного опыта противодействия нелегальной миграции и детерминируемым ею криминальным угрозам, целесообразно проведение выборочных миграционных амнистий в регионах Азиатской части России с низкой плотностью населения и отрицательным миграционным сальдо. Подобные амнистии следует распространить на иммигрантов из стран с близкой россиянам языковой и культурной идентичностью;

- миграционные амнистии следует сочетать с ужесточением ответственности за нарушения миграционного законодательства, что должно способствовать профилактике рецидива подобных правонарушений;

- в целях сокращения количества нелегальных мигрантов и экономии расходов на административное выдворение или депортацию лиц, допустивших нарушения миграционного законодательства в период пребывания в России и желающих добровольно вернутся в страны убытия, освобождать от административной ответственности в случаях выявления подобных правонарушений при пересечении Государственной границы РФ;

- принимая во внимание складывающиеся правовые реалии, целесообразно предусмотреть уголовную ответственность иностранных мигрантов за «злостное нарушение миграционного законодательства», в основе которого может быть, как качественные компоненты «злостности» (на- 
пример, способ и средства допущенного правонарушения), так и её количественная составляющая, а именно, повторность или систематичность;

- учитывая зарубежный опыт государств, наиболее крупных «миграционных реципиентов» и современные требования криминологического обеспечения миграционной безопасности, целе- сообразно наделить ФМС России рядом полицейских функций, включая, права на осуществление оперативно-розыскной деятельности и дознания в отношении преступлений миграционной направленности, а также силовое обеспечение проведения специальных мероприятий и обеспечение собственной безопасности.

\section{Библиография:}

1. О безопасности закон РФ № 390 от 7 декабря 2010 г.: по состоянию на 22 март. 2014 г. - Собрание законодательства РФ. - 2011. № 1.

2. О стратегии национальной безопасности Российской Федерации до 2020 г. [Указ Президента Российской Федерации от 12 мая 2009 г. № 537] // Собрание законодательства РФ. - 2009. - № 20.

3. Концепция государственной миграционной политики Российской Федерации на период до 2025 года [утв. Президентом РФ от 13 июня 2012 г.] // Информационно-правовая система «Гарант».

4. Концепция общественной безопасности в Российской Федерации [утв. Президентом РФ 20.11.2013 г.] // Информационно-правовая система «Гарант».

5. Концепции долгосрочного социально-экономического развития Российской Федерации на период до 2020 года: Распоряжение Правительства Российской Федерации от 17 ноября 2008 г. № 1662-р // Информационно-правовая система «Гарант». Научные статьи и монографии:

6. Никитенко И.В. Миграционная безопасность России: криминологический аспект / Монография. М., 2013. С. $46-48$.

7. Федотенков А.Н. Вопросы демографической и миграционной безопасности // Демографическое развитие и его социально-экономические последствия: мат. международной научно-практ. конф. М.: ГУ ИМЭИ., 2002. С. 152.

\section{References (transliterated):}

1. O bezopasnosti zakon RF № 390 ot 7 dekabrya 2010 g.: po sostoyaniyu na 22 mart. 2014 g. - Sobranie zakonodatel'stva RF. - 2011. № 1.

2. O strategii natsional'noi bezopasnosti Rossiiskoi Federatsii do 2020 g. [Ukaz Prezidenta Rossiiskoi Federatsii ot 12 maya 2009 g. № 537] // Sobranie zakonodatel'stva RF. - 2009. - № 20.

3. Kontseptsiya gosudarstvennoi migratsionnoi politiki Rossiiskoi Federatsii na period do 2025 goda [utv. Prezidentom RF ot 13 iyunya 2012 g.] // Informatsionno-pravovaya sistema «Garant».

4. Kontseptsiya obshchestvennoi bezopasnosti v Rossiiskoi Federatsii [utv. Prezidentom RF 20.11.2013 g.] // Informatsionno-pravovaya sistema «Garant».

5. Kontseptsii dolgosrochnogo sotsial'no-ekonomicheskogo razvitiya Rossiiskoi Federatsii na period do 2020 goda: Rasporyazhenie Pravitel'stva Rossiiskoi Federatsii ot 17 noyabrya 2008 g. № 1662-r // Informatsionnopravovaya sistema «Garant». Nauchnye stat'i i monografii:

6. Nikitenko I.V. Migratsionnaya bezopasnost' Rossii: kriminologicheskii aspekt / Monografiya. - M., 2013. S. $46-48$.

7. Fedotenkov A.N. Voprosy demograficheskoi i migratsionnoi bezopasnosti // Demograficheskoe razvitie i ego sotsial'no-ekonomicheskie posledstviya: mat. mezhdunarodnoi nauchno-prakt. konf. - M.: GU IMEI., 2002. S. 152. 